Pre-publication version

Full final citation:

Allen-Collinson, J (2009) Sporting embodiment: sports studies and the (continuing) promise of phenomenology, Qualitative Research in Sport and Exercise, 1 (3): 279-296

\title{
Sporting embodiment: sports studies and the (continuing) promise of phenomenology
}

\section{Jacquelyn Allen-Collinson}

Updated email: jallencollinson@lincoln.ac.uk 


\title{
Sporting embodiment: sports studies and the (continuing) promise of phenomenology
}

\section{Jacquelyn Allen-Collinson*}

Qualitative Research Unit, School Sport and Health Sciences, University of Exeter, Exeter, UK

(Received 11 December 2008; final version received 1 March 2009)

\begin{abstract}
Whilst in recent years sports studies have addressed the calls 'to bring the body back in' to theorisations of sport and physical activity, the 'promise of phenomenology' remains largely under-realised with regard to sporting embodiment. Relatively few accounts are grounded in the 'flesh' of the lived sporting body, and phenomenology offers a powerful framework for such analysis. A wide-ranging, multi-stranded, and interpretatively contested perspective, phenomenology in general has been taken up and utilised in very different ways within different disciplinary fields. The purpose of this article is to consider some selected phenomenological threads, key qualities of the phenomenological method, and the potential for existentialist phenomenology in particular to contribute fresh perspectives to the sociological study of embodiment in sport and exercise. It offers one way to convey the 'essences', corporeal immediacy and textured sensuosity of the lived sporting body. The use of Interpretative Phenomenological Analysis (IPA) is also critically addressed.
\end{abstract}

Key words: phenomenology; existentialist phenomenology; interpretative phenomenological analysis (IPA); sporting embodiment; the lived-body; Merleau-Ponty

\section{*Email: J.AllenCollinson@exeter.ac.uk}

\section{Acknowledgement}

The author wishes to thank the editor and three reviewers for helpful comments on an earlier draft of the paper. 


\section{Introduction}

Whilst in recent years sports studies have undoubtedly taken to heart vociferous calls 'to bring the body back in' to theorisations of sport and physical activity, the 'promise of phenomenology' (Kerry and Armour, 2000) remains largely under-realised with regard to sporting embodiment. There are relatively few accounts truly grounded in the 'flesh' of the lived sporting body, and phenomenology offers a powerful framework for such description and analysis. Phenomenology, derived from the Greek 'phainomenon', is the study of phenomena, things as they present themselves to, and are perceived in our consciousness. ${ }^{1}$ Kvale (1996: 53) describes it as an approach: 'interested in elucidating both that which appears and the manner in which it appears. It studies the subjects' perspectives of their world; their essential meanings'. The concern with subjectivity, first-person accounts, experience and meaning has, however, sometimes resulted in phenomenology's being erroneously conflated with qualitative research in general, despite its specific philosophical roots and ethos. Described as arguably the major philosophical movement of the twentieth century (Embree and Mohanty, 1997: 1), modern phenomenology emerged from the work of Edmund Husserl (1859-1938), and now spans a wide-ranging, multi-stranded, and interpretatively contested set of perspectives falling under its general rubric. Even one of the key exponents of existentialist philosophy, Maurice Merleau-Ponty, noted (2001: vii) that the question of what phenomenology actually is, had by no means been answered. Part of the problem lies perhaps in the different ontological and epistemological positions underlying the distinctive strands of phenomenology.

Whilst originating in philosophy, forms of phenomenology have been taken up and utilised in a myriad of ways by different disciplines and subjects. In general, though, phenomenology seeks highly detailed, in-depth descriptions of subjective human experiences in specific contexts, and aspires to reveal their 'essences'

\footnotetext{
${ }^{1}$ In contrast 'noumena' are deemed to be the actual objects that produce the phenomena, although the possibility of their 'independent' existence is debated within phenomenology.
} 
(described below); the essential, but always situated, structures of experience as they appear to consciousness. This article gives a brief introduction to phenomenology, and aims to: 1) provide a brief overview of key phenomenological strands; 2) identify central characteristics or qualities of the phenomenological method; 3 ) consider some of the ways in which phenomenology has been operationalised, including within sports and exercise studies, and in the application of Interpretative Phenomenological Analysis; 4) examine the potential of existentialist phenomenology in particular to offer rich analyses of sporting embodiment that evocatively portray the multi-textured experiences of the lived sporting body.

The focus on phenomenology, and the 'lived body' (Leib), the body as linking self and world in an ongoing dynamic inter-relationship, the body of everyday experience, is not, it should be stressed, to advocate some form of idealist, or 'every wo/man', universalist analysis. It is, rather, to suggest some ways in which phenomenologically-inspired insights might be brought to bear on the study of situated sporting experiences. Criticisms of phenomenology as failing to acknowledge sufficiently the power of social-structural constraints upon individuals, interactions and relationships ${ }^{2}$, have been addressed by many forms of more 'social' phenomenological analysis that recognise the structurally-influenced, historically-specific, and socially situated nature of human experience, the intersectionality of identities, and indeed the centrality of relationships within 'human (inter)existence' (Adams, 2007: 24). Although departing from its original 'pure' Husserlian form, more sociologised forms of phenomenology incorporate and develop insights from other theoretical frameworks such as feminism (e.g. Young, 1980, 1998; Bartky, 1990; Butler, 1997), queer studies (e.g. Grosz, 1994; Ahmed, 2007), critical sociology (Hughson and Inglis, 2002) and the phenomenology of 'race' (Alcoff, 1999), to name a few. For, in addition to overcoming Cartesian mind-body dualism and advancing detailed, grounded descriptions of phenomena (two of Husserl's original purposes), phenomenology also

\footnotetext{
${ }^{2}$ See Throop and Murphy (2002) for an analysis of Bourdieu's critique of phenomenology, for example
} 
provides a stance on embodiment that incorporates conceptions of bodies and action as socially- and historically-located, socially-related and interacting from particular structural standpoints. Our bodies are thus acknowledged to be gendered, classed, sexually-'oriented', aged, 'raced', with differing degrees of dis/ability and corporeal variation or in Shildrick's (2001) specific term 'monstrosity', and not always singular or individuated (Tyler, 2001).

\section{Phenomenology: key movements}

Philosophical phenomenology is complex, mutable, multi-stranded, nuanced and contested, and this article can provide only a brief, schematic overview; a flavour of the perspective rather than any detailed analysis. Some of the richness, complexity and tensions are inevitably lost in a resumé such as this. Modern phenomenology as a philosophical stance was originally developed by Edmund Husserl (1931) in an attempt to remedy the inadequacies of 'scientific', 'objective' approaches to studying the nature of human beings and existence. Husserl wanted to acknowledge and address the subjectivity of human experience, which for him constituted the basis of all knowledge. Embree and Mohanty (1997) posit four specific tendencies within the phenomenology movement: realist, constitutive, existentialist and hermeneutic. A brief description of the latter three strands, as particularly apposite to sports studies, is provided below, before focussing specifically on the relevance of existentialist phenomenology and Merleau-Ponty's work for the investigation of sporting embodiment. It should be noted, however, that the strands portrayed here in reality are overlapping and intertwined, and the work of some theorists transcends categories. Labelling can be descriptively useful but also restrictive, and phenomenology is a rich, complex, contested and protean perspective; truly a tangled web in Ehrich's (1999) evocative imagery.

1) Constitutive/transcendental phenomenology are terms applied to Husserl's descriptive phenomenology, which underwent substantial rethinking as his work 
developed. As Embree and Mohanty (1977) indicate, constitutive phenomenology relates broadly to the notion that we are simultaneously in and part of the world into which we are born, that we are aware of, have an 'idea' of, act on the world and 'constitute' ourselves and that world. Husserl's phenomenology has also been termed 'transcendental', in that it seeks to transcend our tacit presuppositions and taken-forgranted assumptions about phenomena, including 'scientific' assumptions, interpretations and abstractions, in order to describe the very 'essences' of phenomena as they present themselves in everyday life. Husserl's phenomenology is epistemological with an idealistic goal, to develop a method to yield absolute essential knowledge or universal laws of facts (Jennings, 1986: 1235, quoted in Ehrich, 1999: 25). He considered phenomenology a rigorous human science that could provide not only detailed descriptions of phenomena but also the ways in which human knowledge is developed, and shared understandings are generated. One of his central ideas was that consciousness is always intentional, directed at something (see Intentionality below).

Whilst acknowledging the role of interpretation, transcendental phenomenology is primarily descriptive, utilising the techniques of 'epoche's' and 'reduction' (defined below) in an attempt to suspend or bracket existing beliefs and presuppositions about a phenomenon prior to its description, in order to arrive at its essential element(s). In Husserl's terms, this is to return 'to the things themselves' ( $z u$ den Sachen selbst). Controversially, Husserl believed it was not only possible to bracket one's own beliefs and assumptions, but also to bracket oneself from the 'natural world' via transcendental reduction and thus to attain pure transcendental consciousness. His idealistic notion of 'transcendental subjectivity' was perhaps not surprisingly subject to trenchant critique, leading Husserl to focus in his later work (1976) upon shared social reality via the concept of the Lebenswelt - the commonsense lifeworld of everyday experience, intersubjectively constructed. This world is not, however, immediately accessible to analysis because of its tacit, taken-for-grantedness. To access the lifeworld requires, Husserl argued, application of the phenomenological method to 
identify and bracket the commonsense, everyday assumptions enveloping the essences of experiences. The concept of the lifeworld was further developed by Alfred Schutz (1972), whose work in turn was adapted by Harold Garfinkel (1984) in his ground-breaking approach, ethnomethodology. More recently, Giorgi (1985) has contributed a significant and detailed body of work within the general spirit of descriptive phenomenology, predominantly applied in the areas of psychology and nursing. Examples of studies within sport and physical activity that use transcendental phenomenology include Morley's (2001) study of breath control in yoga, which also contrasts transcendental with existentialist forms of phenomenology, whilst Moe (2004) uses insights derived from both transcendental and more hermeneutic forms of phenomenology to explore processes of skill acquisition in sport.

2) Hermeneutic phenomenology: Heidegger, Gadamer and Ricoeur are key proponents of hermeneutic phenomenology, an approach that seeks to analyse the context, intention and meaning surrounding a text or representation. Whilst transcendental phenomenology focuses upon the descriptive, hermeneutic phenomenology emphasizes the interpretive. Indeed, Heidegger posited that all description is always fundamentally interpretative, strongly rejecting Husserl's idealistic notion of a transcendental phenomenology, and arguing against the possibility of our being (Sein) as open to bracketing or suspension, given its predating of and pre-eminence over consciousness. Heidegger considered that we are 'thrown into' the world, which we experience directly through a kind of encompassing sight Umsicht - developing a certain know-how or intuitive coping skill. Thus, as Wrathall (2000, quoted in Moe, 2004: 219) notes, we do not encounter the world as a set of meaningless, atomistic elements, indeed for things to be intelligible and meaningful to us, they are 'always already' (in Heidegger's terms) integrated into our world via a background of coping practices. Moe (2004: 219) quotes the example of grasping for a doorknob, and notes that actions such as this do not become meaningful after atomistic information processing, but are always already meaningful to us, seemingly 
'natural'. This notion of things being intelligible only because they are already in our world schema has also been challenged.

Within hermeneutic phenomenology, Gadamer, one of Heidegger's students, took on and further explored the latter's interest in the centrality of language as the fundamental mode of 'being-in-the-world'. Ricoeur's form of phenomenology similarly focuses upon the ways in which meanings are deposited and mediated through language, narrative, myth, religion and art, with a particular emphasis on the narrativity of self. Within sports and exercise, hermeneutic phenomenology has been employed, for example, to examine methodological issues in researching child athletes' experiences of figure skating (Ryba, 2008). Whilst hermeneutic phenomenology certainly offers great possibilities for application in the study of the sporting body, it is upon another strand of phenomenology that the article primarily focuses - on the existential-phenomenological work of Maurice Merleau-Ponty.

3) Existentialist phenomenology and Merleau-Ponty's perception: Existentialist philosophies in general seek understanding of what it means to be human, cohering around fundamental questions such as whether a human nature exists, what it means to be aware of our own mortality. Early proponents of existentialism were Kierkegaard and Nietzsche, and in the twentieth century, key existentialist writers such as Simone de Beauvoir and Jean-Paul Sartre worked closely with Maurice Merleau-Ponty, whose work wedded existentialism and phenomenology (Ehrich, 1999: 28). Heidegger too is often described as an existential phenomenologist, given the ontological slant of his writings, although he himself did not recognise the existentialist label. Existentialist phenomenology provides a 'third way' epistemologically- and ontologically-speaking, commencing not from the assumption of an objective world 'out there', nor from a pure, constituting consciousness, but from a dialogic where world, body and consciousness are all fundamentally intertwined, inter-relating and mutually influencing. One's own body (le corps propre) is the subject of perception, the standpoint from which all things are perceived and experienced; a concept certainly of 
salience within studies of sporting embodiment. Phenomena are thus not merely abstract things out there in the world, separate from human consciousness and experience, but are part of our incarnate subjectivity. We have existential unity with the chair (flesh) of the world, and can experience phenomena at a deeply corporeal, pre-reflective, pre- (or perhaps ultra)-linguistic level. Further, in relation to behaviour, it is 'not directed to the true world or pure being, but to being-for-the animal ... a certain manner of treating the world, of "being-in-the-world"' (Merleau-Ponty, 1963: 125). Our mode of being is thus based on the union of the 'psychic' and the 'physiological'. As illustrative of Heidegger's notion of 'being-in-the-world' (Dasein, 'being there') Merleau-Ponty (1963: 77) gives the example of phantom-limb pain; pain that cannot be purely physiological, nor purely psychological because the person is under no illusion of having an actual physical limb, thus expressing an ambivalent mode of being-in-the-world. In his later work, Merleau-Ponty recast the 'lived body' of his earlier writings as 'chair' (flesh) in order better 'to capture its primordial or elemental character' (Morley, 2001: 75), so that 'being in the world' then became 'flesh-of-the-world', to convey the continuity of world and body.

Existentialist phenomenology also highlights the situatedness of human experience, including gendered experience and behaviour (de Beauvoir, 1974; Young, 1980), and also, importantly for the analysis of much sporting experience, interembodiment, in Merleau-Ponty's (1969) terminology, 'intercorporeality'. For it is argued that the experience of embodiment is 'never a private affair, but is always already mediated by our continual interactions with other human and non-human bodies' (Weiss, 1999: 5). Merleau-Ponty's (1969) focus upon the sensory dimensions of embodiment and his concept of reversibility also have high applicability to studies of sporting embodiment (Hockey and Allen-Collinson, 2007). Reversibility refers to the notion that our sense perceptions are reversible: we both touch and are touched, see and are seen, and so on. So Merleau-Ponty (2001: 93) suggests that the experience of touching, for example, cannot be understood without reference to the possibility of situational reversal. These possibilities are held in a state of constant inter- 
relationship, so our embodied subjectivity inheres in both our touching and our tangibility; the two are inextricably intertwined. In relation to sportspeople, such a relationship is not just with other participants but also with objects such as sports equipment and kit, and the general environment - whether air, water, snow, terrain, and so on (Hockey and Allen-Collinson, 2007).

\section{Phenomenology and Embodiment in Sport and Exercise}

These then are just some of the strands of phenomenology, and its potential for the study of sporting embodiment becomes clear when we recall that a primary task of phenomenology: 'is not to denude human beings, but to reawaken ourselves to the idea that we are beings who live with and through bodies' (Kim 2001: 69). As Connell (1995: 51) evocatively phrases it: 'There is an irreducible bodily dimension in experience and practice; the sweat cannot be excluded'. Given the centrality of the body within sport, it is surprising that, with some notable exceptions, relatively little use has been made explicitly of phenomenological approaches within sports-related studies generally. This point perhaps requires clarification. Some accounts appear implicitly to use phenomenologically-inspired analysis, without naming it as such, whilst others claim to be phenomenological but make scant, superficial, or no reference to any phenomenological theory or theorists. Given the very different ontological and epistemological claims of the various phenomenological strands, leaving unstated the specific phenomenological frame being adopted inevitably raises a number of questions. For the reader fully to appreciate, and to arrive at an informed judgment about the study, s/he needs to be able to locate the account more precisely within the broad sweep of phenomenology.

Despite Whitson's (1976) signalling in the 1970s the potential of the phenomenological method for sports sciences, Kerry and Armour in the 2000s could find few examples of sports-related research that 'fully merit the phenomenological descriptor' (2000: 1). Analogously, as Arnold (1979) and Bain (1995) note, phenomenology has particular relevance to the study of movement, but despite this: 
'little of qualitative research in kinesiology and physical education is grounded in this theoretical perspective' (Bain, 1995: 244). There are, however, perceptive, evocative accounts of phenomenological perspectives on movement applied elsewhere, for example in Engel's (2007) hermeneutic 'aesthetic-phenomenological' analysis of everyday movement as the performance of the dynamic repertoires of existence.

Whilst all strands of phenomenology potentially offer insights into the sporting experience, Merleau-Ponty's form of existentialist phenomenology, with its focus upon embodiment, is particularly well-suited to the in-depth portrayal of the corporeallygrounded experience of sport and physical activity. Indeed, as Kerry and Armour (2000: 7) point out, although not always acknowledged, much work in the sociology of the body generally is rooted in existential philosophy. Given Merleau-Ponty's interest in human consciousness as embodied consciousness, in perception, intentionality, and the ways in which we experience lived-time/space, his work is particularly apposite, and a small but developing corpus draws upon existential phenomenology in examining sport and physical activities.

To give a flavour, the following studies provide some examples (not a comprehensive listing) of the use of a Merleau-Pontian inspired analysis to these areas. In relation to the time-space nexus, for example, Masciotra et al. (2001) provide a detailed phenomenologically-grounded account of spatio-temporal 'distancing' and co-ordination in Karate. The dialectical relationship between 'playerbody-subject' and the lived-space of the playing field has been evocatively portrayed in relation to 'the beautiful game' of soccer, and the 'silky touch' aesthetics of star players (Hughson and Inglis, 2002; Hemphill, 2005). Merleau-Ponty's work has been taken up by various scholars interested in mind-body practices and physical cultures, such as Morley's (2001) interpretation of yoga practice and breath control. McDonald (2007) considers kalarippayattu, a traditional martial art (but also a whole system of spiritual and physical training) of southern India, drawing upon Merleau-Ponty's framework of embodied consciousness and being-in-the-world. Addressing sports and physical activity more generally, Hockey and Allen-Collinson (2007) consider the 
sensuous dimension of the sporting body and the centrality of sense perceptions in participants' experiences of engagement in sport and exercise, utilising insights from Merleau-Ponty's work on the body as subject of perception. As noted, for MerleauPonty (2001) intentionality is a key concern, and perception is inextricably linked to movement, accompanied by intentionality; all elements central to sporting experience.

Crossley (2001: 123) succinctly portrays Merleau-Ponty's position whereby the corporeal schema is 'an incorporated bodily know-how and practical sense; a perspectival grasp upon the world from the "point of view" of the body'. This bodily know-how and practical sense are developed by habit. This does not imply mere mechanical repetition, but, as Crossley (2001: 127) highlights, a practical 'principle' which emerges into the social world via the formulation of meaning, intention and appropriate action, to create the 'habit-body'. So, for example, the sporting body develops not only a cognitive understanding of training and performance but also an embedded corporeal, 'fleshy' knowledge and memory, developed, refined and sedimented over time via habitual, everyday training practices. In this vein and in relation to cricket, Sutton (2007: 764) portrays the role of memory, for the ways in which the past is alive in our embodied actions is typical of mundane human activities, such as talking and driving, as well as more specialist skills such as batting. The development of skill and expertise requires that the performer go beyond a cognitive understanding of what to do, to develop a seemingly 'natural', pre-reflective response to situations. This is well encapsulated by Dreyfus' (1996, cited in Moe, 2004: 220) quoting of Larry Bird, a star basketball player, who indicated: '[A lot of the] things I do on the court are just reactions to situations. . . . A lot of times, I've passed the basketball and not realized I've passed it until a moment or so later'. The next section addresses the phenomenological method specifically, including four key qualities of phenomenology, together with a brief examination of some ways of writing and representing phenomenological research. 


\section{The phenomenological method}

Although the different strands of phenomenology have their own distinctive principles and perspectives, four themes or qualities, derived from Husserlian phenomenology, provide a touchstone in portraying 'the phenomenologcal method', not merely as a set of methods or techniques, but more akin to a distinctive and encompassing worldview (Weltanschauung), the very phenomenological attitude itself.

\section{1) Description}

Given the centrality of the inter-relationship between the perceiver's consciousness and perceived objects within phenomenology, description is never conceived merely as the 'abstract' writing or recording of things without reference to the person perceiving and recording them. Description, however, can mean very different things for phenomenologists working in different traditions, depending upon the degree of interpretative work explicitly involved. For hermeneutic phenomenologists for example, there is no description without interpretation, for any description provides: 'not a copy of the world, but a hermeneutics' (Spurling, 1977: 168). Husserlian forms of descriptive phenomenology, however, have as their aim to 'go back to the things themselves' and to describe experience by suspending as far as possible prior knowledge, assumptions, attitudes and interpretations of the phenomenon in order to arrive at its essential core characteristics and meanings. It is of course acknowledged by many phenomenologists that, contra Husserl's early exhortations, suspending all preconceptions and biases is an impossibility, although 'epochē' is nevertheless a useful research principle.

\section{2) Epochē and reduction}

These elements of Husserlian phenomenology have been subject to intense contestation especially by those working from a more hermeneutical perspective. 'Epochē', from the Greek 'to abstain, stop' or 'to keep a distance from', is used to denote the suspension of taken-for-granted assumptions about a phenomenon, or at least attempts to identify these explicitly and set them aside. It is thus the suspending 
or 'bracketing' of the 'natural attitude', our taken-for-granted, everyday assumptions and presuppositions about something, in order to be able to arrive at and describe its essential characteristics. A form of reduction advocated by Husserl was the 'eidetic'. Here, once the natural attitude has been suspended via epochē, eidetic reduction is used to make sense of what remains, to reduce the phenomenon to an exemplar of an essence or an 'eidos'. For most contemporary phenomenological researchers, however, complete bracketing of the cultural and social situatedness of descriptions and understandings is acknowledged to be an impossibility; we cannot stand outside our cultural frame of reference (including our language structures), although we can make best efforts reflexively to be aware of our assumptions and standpoints, and to render these explicit. Maso (2001: 138) for example notes that theories and interpretations are there in the observing, right from the outset, and: 'To bracket them, if at all possible, would make perception, and therefore experience, impossible'; furthermore, what is bracketed and what appears to consciousness depends very much upon the person doing the bracketing.

Although complete bracketing of assumptions and beliefs is an impossibility, nevertheless in practical research terms Husserl's notion of epochē is useful in encouraging us to adopt a more self-critical and reflective approach in research. In sports studies for instance, it is possible to take the descriptions provided by participants themselves and subject these to analysis by bracketing as much as possible our prior knowledge and assumptions of the phenomenon, for example by making the familiar strange, explicitly questioning and recording our own conceptualisations of the phenomenon, or using researcher triangulation.

\section{3) Essences}

The purpose of eidetic reduction is to distil a phenomenon, to reduce it down to its core meaning, its 'eidos', devoid of the usual tacit, taken-for-granted assumptions and preconceptions enveloping it. For Husserl, a central aim of phenomenology was the 'discovery of the essences of experience', the essential structures of experience, in 
order to create a 'systematic and disciplined methodology for the derivation of knowledge' (1931, quoted in Kerry and Armour, 2000:3). But, as Ehrich (1999: 23) notes, for later phenomenologists such as Merleau-Ponty, arriving at such description of the phenomenon is not the culmination, but merely a starting point in understanding the relationships of the experience. The concept of 'essences' has been widely debated, particularly in relation to notions of universality and the 'independence' of such essences from social context. It is clear, for example, that for Merleau-Ponty (1963) with his emphasis on the situatedness of experience, such essential structures are indeed socially constituted, culture- and context-bound rather than universal. Similarly, Giorgi's (1985) work focuses upon 'typical' structures that are always inevitably context-dependent.

\section{4) Intentionality}

Another key claim of phenomenology, originating in Husserl's work and critically developed by Merleau-Ponty, is that consciousness is always consciousness of something; it is thus intentional, directed or orientated towards something or someone. Intentionality in this context relates not so much to the element of 'intent', but more to 'directedness'. As Willig (2008: 52) neatly phrases it: 'Intentionality allows objects to appear as phenomena', and explains why different people can and do perceive and experience the 'same' environment in radically different ways. Thus, it is argued, a thing must present itself to us as something recognizable and always already in our schema of the world, in order to be perceived and recognised as such. Our being-in-the-world consists in projecting purposes and goals, which structure and influence our situatedness (Young, 1980: 140). Ahmed (2007: 2) for example portrays this in relation to the orientation and intentionality of emotions; our emotions being always 'directed' toward objects, so that when we experience fear, we feel fear of something (however nebulous that might be). As she further notes (2007: 3), orientations shape not only how we inhabit space, but how we apprehend the world of shared inhabitance, to whom or what we direct our energy and attention. MerleauPonty (2001) distinguishes between two kinds of intentionality: intentionality of acts, 
when we consciously and voluntarily take up a position; and operative intentionality, a kind of pre-reflective intentionality, a tacit, 'background-noise' setting to our lives, only brought to light via the phenomenological reduction (see Reuter, 1999 for a detailed explanation).

These then are four central qualities or elements within the phenomenological method, which, as Kerry and Armour (2000: 8) note, 'is the phenomenological approach itself'. This 'method' for deriving knowledge is perhaps better described as a phenomenological attitude, an orientation to the world, a way of looking, 'an attitude of attentiveness to the things of immediate experience' (Van den Berg, 1972), rather than any set of prescribed techniques or procedures, although these have been advocated by some. For many phenomenologists, however, any method that can produce detailed, rich, in-depth, textured, descriptions of participants' own subjective, concrete lived experiences of a phenomenon, has the potential to provide the basic data for application of phenomenological analysis or empirical phenomenological reflection (EPR) (Colaizzi, 1973). Indeed phenomenological description and analysis have been applied to data derived from a spectrum of methods ranging from semistructured interviews (for example, Hiskey et al., 2008) through to autoethnographic data (for example, Hockey and Allen-Collinson, 2007), or at least to the autophenomenographic elements of the latter. Examples of research that fully acknowledges and respects phenomenological ethos and principles are provided by van Manen (1990) (hermeneutic perspective on pedagogy), Todres (2007) (in relation to psychotherapy and spirituality), Moustakas (1994) and Giorgi (1985) (using existential perspectives).

Although word limit precludes a fuller discussion of the wide range of ways in which phenomenological research has been and might be designed and conducted, there is a burgeoning literature of 'practitioner-related' phenomenology, particularly within psychology, health psychology and nursing (e.g. Colaizzi, 1978; Moustakas, 1994; Dale, 1996; Willig, 2007). There have been numerous and varied efforts at operationalising phenomenology in a specific empirical approach, which seeks to obtain 
'comprehensive descriptions that provide the basis for a reflective structural analysis that portrays the essences of the experience' (Moustakas, 1994: 13). Giorgi's (1985) phenomenological method, for example, uses a Husserlian-inspired approach to address psychological problems, and he provides detailed guidelines for undertaking this form of research (see Willig, 2008: 55), which can also be applied to sporting phenomena. He advocates:

1) the collection of concrete, 'naïve' descriptions of the phenomenon from participants', as co-researchers;

2) the researcher's adoption of the phenomenological attitude;

3) an impressionistic reading of each description to gain a feel of the whole;

4) the in-depth re-reading of the description to identify 'meaning units', which capture specific aspects of the whole;

5) identifying and making explicit the psychological significance of each meaning unit;

6) the production of a general description of the structure(s) of the experience, with the aim of letting 'the phenomena speak for themselves' (Giorgi, 1985: 151).

Moving away from the more Husserlian end of the spectrum, Interpretative Phenomenological Analysis (IPA) provides a popular, accessible and relatively straightforward research approach that has been extensively applied within psychology, especially health psychology, and health and medicine-related studies, also finding favour with some sport and exercise psychologists (see for example, Shepherd et al. 2006; Jones and Lavallee, 2009). Despite its undoubted potential with regard to the much-needed focus upon patients'/participants' own subjective experiences, and its burgeoning popularity, there are certain problems with some studies employing the IPA framework when viewed from the more phenomenological, 'open' and participant-focussed end of the phenomenological spectrum. (For other criticisms of IPA, see for example, Parker (2005) from a narrative analytic stance.) 
This is not to decry, or deny in any way the usefulness of IPA-based studies, some of which are excellent, perceptive and phenomenologically acute, but merely to raise awareness of some of the problems that may occur when studies depart radically from a phenomenological grounding and ethos, or are not explicit about how and why they employ phenomenology specifically, as opposed to other qualitative approaches.

\section{Interpretative Phenomenological Analysis (IPA): caveat}

The aim of IPA is to explore in detail the sense-making activities of participants in relation to their own subjective experiences. ${ }^{3}$ This concern with subjectivity, firstperson accounts, experience, meaning and sense-making has sometimes resulted in a confusing conflation with qualitative research in general, however. So, for instance, an oft-cited rationale for employing phenomenology in IPA-bases studies is that it enables the exploration variously of participants' subjectivity, experiences and perceptions. As these are by no means specific to phenomenology but a general goal of much qualitative research in general, the rationale is fundamentally blunted and it is left to the reader to speculate as to why a phenomenological perspective in particular was chosen.

A further problem lies with the phenomenological/interpretational balance in some IPA-based research. As Brocki and Wearden (2006) note, IPA is phenomenological in so much as it is concerned with individuals' subjective reports rather than with 'objective' accounts, but also interpretative in its recognition of the researcher's interpretative role in the analysis. It should be said, however, that this phenomenological/interpretational balance can prove difficult to maintain, and a good deal of IPA-based research strays a considerable way from any phenomenological grounding, although some studies do retain strong elements of phenomenological ethos. Nicholls et al., (2005) for example use an IPA approach, underpinned by clearly articulated phenomenological principles, to investigate golfers' coping strategies in relation to performance-related stressors during competitions. At the other end of the

\footnotetext{
${ }^{3}$ See Smith (2004) and Smith and Osborn (2003) for good discussions of IPA.
} 
spectrum, whilst interesting in their own right, with some IPA-based studies it is difficult to discern in what ways they are actually distinguishable from qualitative research in general. This is especially so where there is scant, if any, reference to phenomenology as theory (let alone phenomenological principles) in anything other than name. Warriner and Lavallee's (2008) excellent study of retirement experiences amongst former elite gymnasts, for example, provides an interesting, thoughtful and insightful analysis but its phenomenological grounding is not evident in the write-up, although the authors state clearly that a phenomenological approach was indeed adopted (2008: 303). Somewhat analogous to the way in which 'grounded theory' is often cited as constituting part of a methodological approach, but then no further reference made to its principles or the detail of its processes, 'phenomenology' is sometimes adopted in talismanic fashion, with no real attempt to engage with phenomenology as epistemology, ontology or indeed methodology in its wider, philosophical sense.

Following on from this lack of phenomenological engagement, problems with IPA, at least from a 'stronger' phenomenological perspective, cohere around the actual methods used for data collection and analysis. Semi-structured interviews are described as the primary method for IPA by key proponents (Smith and Osborn, 2003), and forms of thematic content analysis are often used to examine participants' understandings of, perceptions of, and beliefs about a phenomenon (see for example, Chapman and Smith, 2002; Moore et al. 2008). As the purpose of phenomenology is to assemble descriptions of, and above all to be faithful to the direct lived experiences of research participants, using approaches such as semi-structured interviews can engender problems. Here, researcher preconceptions, including the theoretical, can filter through at an earlier stage and to a greater extent than in approaches more conducive to participants' own constructions of experience, such as in unstructured interviews or participant diaries, for example. Some IPA researchers even indicate prior to interview the precise areas participants will be 'required' to expand upon (e.g. Lavallee and Robinson, 2007). In a literature review of IPA-based research in health 
psychology, Brocki and Wearden (2006: 91) found that IPA interviews were often designed on the basis of extant research findings, theory or models, even including positivistic and quantitative work (e.g. Flowers et al., 2000), highly problematic from a phenomenological angle. Pre-existing research, concepts and models also structure some IPA studies in sport and exercise (e.g. Shepherd et al., 2006; Gillison et al., 2008; Warriner and Lavallee, 2008). Whilst all researchers necessarily hold preconceptions about their topic of enquiry, adherence to tightly preconceived frameworks based heavily on existing theory, models and constructs, sits very uneasily with the openness-to-the-world of, and faithfulness to participant-generated concepts and accounts held to be essential for phenomenological research.

Preconceptions and assumptions may also creep in at the data analytic stage, another key element in IPA, if pre-defined category systems are used to structure the thematic analysis. Warriner and Lavallee (2008), for example, in their IPA study of the retirement experiences of retired elite female gymnasts explain that their research 'instrument' was: 'a predetermined interview schedule [which] was developed employing standardized open-ended questions in addition to tailored probes... The schedule was underpinned by an extensive review of the extant literature on retirement from elite sport...' (p. 304). Again, it should be stressed that these studies are often interesting and well-conceived qualitative projects, but it is the use of predefined concepts, categories and even extant models that inevitably raises some questions, given phenomenology's commitment to epochē and the bracketing of such presuppositions and prior assumptions.

In many IPA studies, too, the production of general statements of the phenomenon/a studied involves the researcher's translation of 'units of meaning' into second-order constructs of the subject or disciplinary language, to produce a general description of the structures of the experience. Researchers vary greatly in the extent to which they undertake such translational work and apply theoretical or 'scientific' constructs to participant-recounted experiences. Mindful of Husserl's original exhortation to bracket such 'scientific' explanations and assumptions, however, the 
dangers of 'over-interpreting', and indeed overwriting participants' accounts to conform to social scientific or other frameworks, loom large. Much may indeed be lost in translation. And, as Willig (2007: 216) reminds us, 'the researcher's choice of label for the phenomenon of interest is not merely a descriptive act but a constitutive one'; this risks departure and divergence from the participants' own lived experience of the phenomenon. Such abstraction and imposition of labels clearly create potential problems with IPA-based studies that stray too far away from the general principles of phenomenology, particularly in relation to phenomenology's insistence that participants are the experts in the phenomenon/a under investigation. It is therefore most peculiar to find that some IPA-based studies do not even include substantial quotations from their participants, as Brocki and Wearden (2006) discovered in their research review. Moreover, in relation to the degree of interpretative work undertaken by IPA researchers, whilst complete epochē is impossible, and researcher interpretation is unavoidable, nevertheless abandoning entirely Husserl's original exhortation to bracket - or at least attempt explicitly to identify - the researcher's own characteristics, preconceptions, theories of interest, and interpretations, runs deeply counter to phenomenological attitude and ethos, where a high degree of reflexivity is requisite.

As Gruppetta (2004: 4) notes phenomenology in general has sometimes been criticised because the vast majority of phenomenological researchers do not participate themselves in the processes they study, but rely upon second-hand accounts. Although the use of second-hand accounts need not necessarily be construed as a weakness of phenomenology or IPA per se (or indeed of any research approach), it is incumbent upon IPA researchers without substantial 'insider experiential knowledge' of the areas they study to proceed with particular caution in imposing their own meanings and constructs upon the accounts of their 'expert' participants, and to articulate explicitly the degree of interpretation and 'analytic licence' being employed. Given that the phenomenological method seeks above all to understand phenomena from the perspective of those studied (Creswell, 1998: 274), there are clear dangers in 
a researcher's imposition of meanings, categories, concepts and terminology upon her/his participants' experiences. For, as Garfinkel warned in relation to his 'unique adequacy requirement':

... for the analyst to recognize, or identify, or follow the development of, or describe phenomena of order in local production of coherent detail, the analyst must be vulgarly competent to the local production and reflexively natural accountability of the phenomenon or order he (sic) is "studying". (2002, p. 175) (italics in original)

Autoethnographic phenomenology or 'autophenomenography' is one possible means of overcoming some of the problems of using second-hand accounts, but todate has been rarely utilised (e.g. Hockey and Allen-Collinson, 2007). Gruppetta (2004) argues that if the researcher studies a phenomenon rather than a 'cultural place', then the appropriate term would be autophenomenography, rather than autoethnography, which latter focuses upon an individual's experiences qua member of a cultural/subcultural group. Autophenomenographic accounts could therefore be used either as sole data source - as in phenomenological single-case studies (e.g. Jones and Lavallee, 2009) - or in conjunction with other participants' accounts. These could then provide the rich, evocative, textured descriptions of first-person experience, including sporting embodiment, so central to the phenomenological quest to bring to life and to share with others the felt, lived, embodied experience.

A final criticism of IPA raised here is the tendency for some researchers to use highly abstract language in their general statements of phenomena and thus to lose the feel, vitality, richness, textures and grounded 'bodyfulness' of the lived experience. Todres (2007: 9) for examples warns that 'One could describe the general themes of an experience in such an abstract way that the qualities are devitalised...', a tendency fundamentally anathema to the phenomenological project. So in light of this, the final section considers briefly potential forms of writing/representing phenomenological accounts. 


\section{Writing and representation}

Writing and representation are fundamental concerns within phenomenology. In order to bring to life the essential structures of lived experience for the reader, to engage in 'the breathing of meaning' (Van Manen, 1990: 36), the researcher has to be able to convey accurately, powerfully, evocatively and many would advocate aesthetically and poetically (but always inevitably only partially) the phenomena described, whether via writing or re/presentational forms such as ethnodrama and other performative, audience-interactive forms (see e.g. Hopper et al., 2008; Todres, 2008). Phenomenology seeks to provide highly textured, evocative descriptions that locate the specifics of individual experience within broader, more general structures of human experience. Importantly, these accounts aim to generate a feeling of understanding in the reader (Todres, 2007: 9) thus linking the embodiment of researcher, research participant(s) and reader. As Merleau-Ponty (2001) notes in relation to structures of experience, these are 'lived' rather than 'known', and understanding occurs at a pre-reflective and corporeal as well as at a cognitive level. 'Full-bodied', corporeally-textured, sensuously-detailed descriptions are of particular salience within accounts of sporting embodiment.

In addition to unstructured interview-derived data or personal diaries, a source of detailed, highly personal, grounded and evocative accounts can be found within the personal narratives of sports participants themselves (e.g. Sparkes and Smith, 2007), including phenomenological elements within some autoethnographies, as noted above. Although there is not the scope fully to consider its potential here, it is worth noting that autoethnographic and/or autophenomenographic genres fuse author/researcher/researched, with the purpose of using the researcher's personal lived experience to illuminate the phenomenon under study (Ellis and Bochner, 2000), to invite readers into the text, to relive the experience rather than merely analyse it at least at a certain level. Authors within this developing literature in sports studies (e.g. Sparkes, 2002; Denison and Markula, 2003; Allen-Collinson and Hockey, 2001; 2005) depart from more orthodox, 'author-absent' textual accounts of sporting 
embodiment, by constructing forms of narrative that seek to portray in a first-person, evocative-analytic fashion the lived-body sporting experience. Although little of this oeuvre formally applies phenomenological theory or method to the data, the potential for phenomenological analysis is clearly discernible particularly in relation to highly embodied and situated experiences such as McCarville's (2007: 163) vivid description of the nausea-generating, disorientating moments after his completion of the swimming component of an Ironman triathlon, or Hockey and Allen-Collinson's (2007: 125) portrayal of the mixed sensations of the running-body's muscular gradual 'reawakening' after a period of injury. Autophenomenography is thus just one possible means of generating the rich, body-ful, fleshy, grounded and evocative descriptions of the body in sport and exercise, encouraging us to bring the sweat 'back in', rather than to exclude it from our analyses (c.f. Connell, 1995).

\section{Concluding (but never final) thoughts}

Having portrayed some of the key strands of phenomenological thought, and the ways in which existentialist phenomenology in particular might offer fresh descriptive and analytic insights into the study of sporting embodiment, it is clear that there are sound reasons for incorporating phenomenological perspectives into the theoretical and methodological pantheon of approaches to investigating sporting experience. For, despite a growing corpus of research literature on the sporting body, this particular 'subject' has often been addressed at an abstract, theoretical level. We still find relatively few studies actually grounded in the carnal, 'fleshy', lived, richlytextured realities of the moving, sweating, sensuous sporting body, which of course also holds meanings, significances, purposes and interests. This is not to advocate phenomenology as the only or even the best way of pursuing qualitative investigations into sporting embodiment, but to propose it as a complementary theoretical and methodological avenue. Rich phenomenological descriptions and analyses can promote a re/consideration of the essential structures of sporting and physical activity experience (corporeal, emotional and so on) in context, and encourage reflection upon, and empathic understanding of how it actually feels to be a sporting/exercising body. 
As Todres (2008: 1571) perceptively describes, the 'epistemic body' can implicitly 'hold' multiple meanings and significances in ways much more holistic and interrelated than abstract thought. These meanings, felt in the body, can become the source of thoughts and words that point to greater wholes, so that: 'The greater wholeness can never be fully summarized, but its impact can be somewhat felt and held through the evocative power of words' (2008: 1571). As Willig (2007) notes in relation to her phenomenological research on extreme sports, language is a central issue for phenomenologists, given that it both facilitates and limits the expression of experience. Although phenomenology, as with any theoretical or methodological approach, can never fully capture or summarise the totality of an experience (and is explicit about this partialness), this article has suggested how phenomenologicallyinspired perspectives - both theoretical and methodological - might bring fresh insights to the portrayal of the lived sporting and exercising body. But perhaps, I should say lived sporting bodies, to re-emphasize our individual, biographicallyspecific, historically- and socially-situated experiences of sporting embodiment. For developments in the social-phenomenological field itself, such as the 'queering' of phenomenology (e.g. Ahmed, 2007), provide fertile grounds for its linkage with newer theoretical perspectives within sport studies, together with continued development of its longer-standing connection with feminism (e.g. Young, 1980, 1998). This addresses criticisms of phenomenology as being, in some forms at least, neglectful of social structure and of 'difference'.

Phenomenology can provide not only a theoretical and methodological framework for examining human subjectivity and embodiment in general, but also for investigating the specifics of socially-located, socially-related and interacting bodies. With its focus upon the essential (but always context-dependent) meanings of phenomena, it can portray sporting embodiment vividly and evocatively. Phenomenology seeks to remain 'true' to the expert accounts of those who experience it directly, rather than creating abstract theories without due attention to, and analytic grounding in those accounts. As McCall (1983: 57; quoted in De Castro, 2003: 47) 
reminds us: 'To ignore the phenomena of conscious life just as they are given in experience is to abnegate the ultimate source of all knowledge in favour of physicalistic dogma'. Although, in common with any research approach, there are undoubted limitations to phenomenology, the exhortation to remain true to the experiential accounts of participants themselves and to examine phenomena in context rather than too far abstracted from their 'grounding' - corporeal and conscious - is nevertheless a sound one. Phenomenology provides us with a way of combining the personal, idiographic and the general, ethnographic, and also as Todres (2007) notes, of returning texture to structure, and creating rich descriptions that produce a feeling of understanding in the reader, of bodily knowing and sense-making as well as cognitive knowledge.

\section{Notes on contributor}

Jacquelyn Allen-Collinson is based in the Qualitative Research Unit in the School of Sport \& Health Sciences, University of Exeter. Her research interests cohere around the sociology and phenomenology of the body, including sporting bodies and injured bodies; identity and identity work; intimate partner abuse and violence; autophenomenography. 


\section{References}

Adams, W.W. (2007) The Primacy of Interrelating: Practicing Ecological Psychology with Buber, Levinas, and Merleau-Ponty. Journal of Phenomenological Psychology, 38: $24-61$

Ahmed, S. (2007) Queer Phenomenology: Orientations, Objects, Others. Durham, NC: Duke University Press.

Alcoff, L. (1999) Towards a Phenomenology of Racial Embodiment. Radical Philosophy, 95: 8-14.

Allen-Collinson, J. and Hockey, J. (2001) Runners' Tales: Autoethnography, Injury and Narrative. Auto/Biography, IX (1 \& 2): 95-106.

Allen Collinson, J. and Hockey, J. (2005) Autoethnography: Self-indulgence or Rigorous Methodology. In: M. McNamee (Ed.) Philosophy and the Sciences of Exercise, Health and Sport, pp. 187-202. London: Routledge.

Arnold, P. J. (1979) Meaning in Movement, Sport and Physical Education. London: Heinemann Education.

Bain, L.L. (1995) Mindfulness and Subjective Knowledge. Quest 47: 238-253.

Bartky, S. (1990) Femininity and Domination: Studies in the phenomenology of oppression. New York: Routledge. 
Brocki, J.M. and Wearden, A.J. (2006) A Critical Evaluation of the Use of Interpretative Phenomenological Analysis (IPA) in Health Psychology. Psychology and Health, 21 (1): 87-108.

Butler, J. (1997) Performative Acts and Gender Constitutions: An essay in phenomenology and feminist theory. In K. Conboy, N. Medina and S. Stanbury (Eds) Writing on the Body: Female embodiment and feminist theory. New York: Columbia University Press.

Chapman, E. and Smith, J.A. (2002) Interpretative Phenomenological Analysis and the New Genetics. Journal of Health Psychology, 7(2) 125-130.

Colaizzi, P.F. (1973) Reflection and Research in Psychology: A Phenomenological Study of Learning. Dubuque, Iowa: Kendall/Hunt Publishing Co.

Colaizzi, P. F. (1978) Psychological Research as the Phenomenologist Views It. In R.S. Valle and M. King (Eds) Existential-phenomenological Alternatives for Psychology. Oxford: Oxford University Press.

Connell, R.W. (1995) Masculinities. Berkeley, CA: University of California Press.

Creswell, J.W. (1998) Qualitative Inquiry and Research Design: Choosing among Five Traditions. London: Sage.

Crossley, N. (2001) The Social Body: Habit, Identity and Desire. London: Sage.

Dale, G.A. (1996) Existential Phenomenology: Emphasizing the experience of the athlete in sport psychology research. The Sport Psychologist 10: 307-321. 
de Beauvoir, S. (1974) The Second Sex. New York: Vintage Books.

De Castro, A. (2003) Introduction to Giorgi's Existential Phenomenological Research Method. Psicología desde el Caribe. Universidad del Norte, 11: 45-56.

Denison, J. and Markula, P. (Eds) (2003) Moving Writing: Crafting Movement in Sport and Research. New York: Peter Lang.

Dreyfus, H.L. (1996) The Current Relevance of Merleau-Ponty's Phenomenology of Embodiment. Electronic Journal of Analytic Philosophy, 4. Retrieved October 3, 2008, from: http://ejap.louisiana.edu/EJAP/1996.spring/dreyfus.1996.spring.abs.html

Ehrich, L.C. (1999) Untangling the Threads and Coils of the Web of Phenomenology. Education Research and Perspectives, 26 (2): 19-44.

Ellis, C. and Bochner, A. (2000) Autoethnography, Personal Narrative, Reflexivity: Researcher as Subject. In N. Denzin and Y. Lincoln (Eds) Handbook of Qualitative Research, pp. 733-768. London: Sage.

Embree, L. and Mohanty, J.N. (1997) Introduction. In L. Embree et al. (Eds) Encyclopedia of Phenomenology (pp. 1-10). Dordrecht: Kluwer Academic Publishers.

Engel, L. (2007) The Dance of the Now - Poetics of Everyday Human Movement. Forum Qualitative Sozialforschung / Forum: Qualitative Social Research, 9 (2): Art. 35. Retrieved October 19, 2008, from: http://www.qualitative-research.net/index.php/fqs/article/viewArticle/388/844. 
Flowers, P., Marriott, C. and Hart, G. (2000) 'The Bars, the Bogs and the Bushes': The impact of locale on sexual cultures. Culture, Health and Sexuality, 2: 69-86.

Garfinkel, H. (1984) Studies in Ethnomethodology (Revised edition). Polity Press/Blackwell.

Garfinkel, H. (2002). Ethnomethodology's program: Working out Durkheim's aphorism (edited by A. Warfield Rawls). New York: Rowman \& Littlefield.

Gillison, F., Osborn, M., Standage, M. and Skevington, S. (2008 in press). Exploring the experience of introjected regulation for exercise across gender in adolescence. Psychology of Sport and Exercise. doi:10.1016/j.psychsport. 2008.10.004

Giorgi, A. (Ed) (1985) Phenomenology and Psychological Research. Pittsburgh: Duquesne University Press.

Grosz, E.A. (1994) Volatile Bodies: Toward a Corporeal Feminism. Bloomington, IN: Indiana University Press.

Gruppetta, M. (2004) Autophenomenography? Alternative uses of autobiographically based research. In P. L. Jeffery (Ed.) Association for Active Researchers in Education (AARE) Conference Paper Abstracts - 2004. Sydney: AARE. Retrieved May 5, 2009 from: http://www.aare.edu.au/04pap/gru04228.pdf

Hemphill, D. (2005) Deeper Inside the Beautiful Game. Journal of the Philosophy of Sport, XXXII: 105-115. 
Hiskey, S., Luckie, M., Davies, S. and Brewin, C. (2008). The Phenomenology of Reactivated Trauma Memories in Older Adults: A preliminary study. Aging and Mental Health, 12 (4): $494-498$.

Hockey, J. and Allen-Collinson, J. (2007) Grasping the Phenomenology of Sporting Bodies. International Review for the Sociology of Sport, 42 (2): 115-131.

Hopper, T. F., Madill, L. E., Bratseth, C. D., Cameron, K. A., Coble, J. D. and Nimmon, L. E. (2008) Multiple Voices in Health, Sport, Recreation, and Physical Education Research: Revealing Unfamiliar Spaces in a Polyvocal Review of Qualitative Research Genres. Quest, 60: 214- 235.

Hughson, J. and Inglis, D. (2002) Inside the Beautiful Game: Towards a MerleauPontian phenomenology of soccer play. Journal of the Philosophy of Sport, XXIX: 115.

Husserl, E. (1931) Ideas (trans. W. R. Boyce Gibson). London: George Allen \& Unwin.

Jennings, J.L. (1986) Husserl Revisited: The forgotten distinction between psychology and phenomenology. American Psychologist, 41 (11): 1231-1240.

Jones, M.I. and Lavallee, D. (2009) Exploring Perceived Life Skills Development and Participation in Sport. Qualitative Research in Sport and Exercise, 1(1): 36-50.

Kerry, D.S. and Armour, K.M. (2000) Sports Sciences and the Promise of Phenomenology: Philosophy, Method, and Insight. Quest, 52 (1): 1-17.

Kim, H.W. (2001) Phenomenology of the Body and its Implications for Humanistic Ethics and Politics. Human Studies, 24: 69-85, 
Kvale, S. (1996) Interviews: An Introduction to Qualitative Research Interviewing. London: Sage.

Lavallee, D. and Robinson, H.K. (2007) In Pursuit of an Identity: A qualitative exploration of retirement from women's artistic gymnastics. Psychology of Sport and Exercise, 8: 119-141

Masciotra, D., Ackermann, E. and Roth, W.-M. (2001) 'Maai": The Art of Distancing in Karate-Do: Mutual attunement in close encounters. Journal of Adult Development, 8 (2): 119-132.

Maso, I. (2001) Phenomenology and Ethnography. In P. Atkinson, S. Delamont, J. Lofland and L. Lofland (Eds) Handbook of Ethnography, pp. 136-144. Thousand Oaks, CA: Sage.

McCall, R. (1983) Phenomenological Psychology. Madison: The University of Wisconsin Press.

McCarville, R. (2007) From a Fall in the Mall to a Run in the Sun: One Journey to Ironman Triathlon. Leisure Sciences, 29 (2): 159-173.

McDonald, I. (2007) Bodily Practice, Performance Art, Competitive Sport: A Critique of Kalarippayattu, Martial Art of Kerala. Contributions to Indian Sociology, 41 (2): 143168.

Merleau-Ponty, M. (1963) The Structure of Behaviour (trans. A.L. Fisher). Boston: Beacon Press. 
Merleau-Ponty, M. (1969) The Visible and the Invisible. (trans. A. Lingis). Evanston, III: Northwestern University Press.

Merleau-Ponty, M. (2001) Phenomenology of Perception (trans. C. Smith). London: Routledge \& Kegan Paul.

Moe, V. F. (2004) How to Understand Skill Acquisition in Sport. Bulletin of Science, Technology \& Society, 24 (3): 213-224.

Moore, T., Norman, P., Harris, P.R. and Makris, M. (2008) An Interpretative Phenomenological Analysis of Adaptation to Recurrent Venous Thrombosis and Heritable Thrombophilia: The Importance of Multi-causal Models and Perceptions of Primary and Secondary Control. Journal of Health Psychology, 13 (6) 776-784.

Morley, J. (2001) Inspiration and Expiration: Yoga Practice Through Merleau-Ponty's Phenomenology of the Body. Philosophy East and West, 51 (1): 73-82.

Moustakas, C. (1994) Phenomenological Research Methods. London: Sage.

Nicholls, A., Holt, N.L. and Polman, R.C.J. (2005). A Phenomenological Analysis of Coping Effectiveness in Golf. The Sport Psychologist, 19 (2): 111-130.

Parker, I. (2005) Qualitative Psychology: Introducing radical research. Maidenhead: OU Press. 
Reuter, M. (1999) Merleau-Ponty's Notion of Pre-reflective Intentionality. Synthese, 118: $69-88$.

Ryba, T. (2008) Researching Children in Sport: Methodological reflections. Journal of Applied Sport Psychology, 20 (3): 334-348.

Schutz, A. (1972) The Phenomenology of the Social World. London: Heinemann.

Shepherd, D.J. Lee, B. and Kerr, J.H. (2006) Reversal Theory: A suggested way forward for an improved understanding of interpersonal relationships in sport. Psychology of Sport and Exercise, 7 (2): 143-157.

Shildrick, M. (2001) 'You are there, like my skin': Reconfiguring relational economies. In S. Ahmed and J. Stacey (Eds) Thinking Through the Skin, pp. 160-173. London: Routledge.

Smith, J.A. (2004) Reflecting on the development of interpretative phenomenological analysis and its contribution to qualitative research in psychology. Qualitative Research in Psychology, 1: 39-54.

Smith, J. A. and Osborn, M. (2003) Interpretative Phenomenological Analysis. In J.A. Smith (Ed.) Qualitative Psychology: A Practical guide to Research Methods. London: Sage.

Sparkes, A.C. (Ed.) (2002) Telling Tales in Sport and Physical Activity. Champaign, Ill: Human Kinetics.

Sparkes, A.C. and Smith, B. (2007) Disabled Bodies and Narrative Time: Men, Sport, and Spinal Cord Injury. In J. Hargreaves and P.A. Vertinsky, P.A. (Eds) Physical Culture, Power, and the Body, pp. 158-175. London: Routledge. 
Spurling, L. (1977) Phenomenology and the Social World. The Philosophy of MerleauPonty and its Relation to the Social Sciences. London: Routledge \& Kegan Paul.

Sutton, J. (2007) Batting, Habit and Memory: The Embodied Mind and the Nature of Skill. Sport in Society, 10 (5), $763-786$.

Throop, C.J. and Murphy, K.M. (2002) Bourdieu and Phenomenology: A critical assessment. Anthropological Theory 2 (2): 185-207.

Todres, L. (2007) Embodied Enquiry: Phenomenological Touchstones for Research, Psychotherapy and Spirituality. New York: Palgrave Macmillan.

Todres, L. (2008) Being with That: The Relevance of Embodied Understanding for Practice. Qualitative Health Research 18 (11): 1566-1573.

Tyler, I. (2001) Skin-tight: Celebrity, pregnancy and subjectivity. In S. Ahmed and J. Stacey (Eds), Thinking Through the Skin, pp. 69-83. London: Routledge.

Van den Berg, J.H. (1972) A Different Existence. Pittsburgh: Duquesne University Press.

van Manen, M. (1990) Researching Lived Experience: Human Science for an Action Sensitive Pedagogy. New York: State University of New York Press.

Warriner, K. and Lavallee, D. (2008) The Retirement Experiences of Elite Female Gymnasts: Self identity and the physical self. Journal of Applied Sport Psychology, 20: 301-137. 
Weiss, G. (1999) Body Images: Embodiment as Intercorporeality. London: Routledge.

Whitson, D. (1976) Method in Sport Sociology: The potential of a phenomenological contribution. International Review for the Sociology of Sport, 11 (4): 53-68.

Willig, C. (2007) Reflections on the Use of a Phenomenological Method. Qualitative Research in Psychology, 4: 209-225.

Willig, C. (2008) Introducing Qualitative Research in psychology (2 ${ }^{\text {nd }}$ ed.). Milton Keynes: Open University Press/McGraw Hill.

Wrathall, M.A. (2000) Background Practices, Capacities, and Heideggerian Disclosure. In M. Wrathall \& J. Malpas (Eds.) Heidegger, Coping and Cognitive Science: Essays in Honour of Hubert L. Dreyfus (Vol. 2), pp. 93-114. Cambridge, MA: MIT Press.

Young, I.M. (1980) Throwing like a Girl: A phenomenology of feminine body comportment motility and spatiality. Human Studies 3: 137:156.

Young, I.M. (1998) 'Throwing Like a Girl': Twenty Years Later'. In D. Welton (Ed.) Body and Flesh: A Philosophical Reader, pp. 286-290. Oxford: Blackwell. 